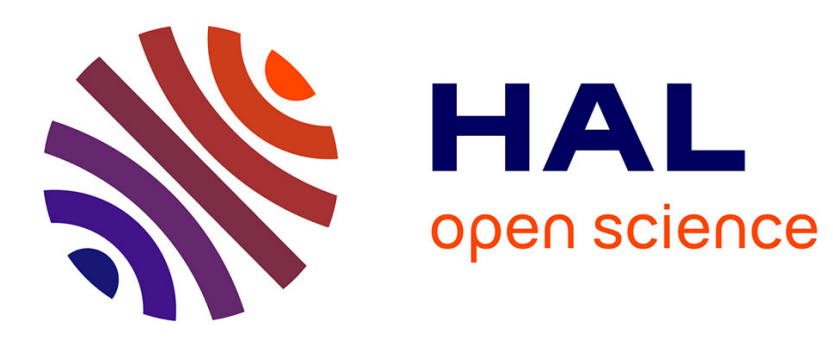

\title{
Speed and Atmosphere Influences on Nanotribological Properties of $\mathrm{NbSe} 2$
}

Philippe Bilas, Laurence Romana, Francois Bade, Karl Delbe, Jean-Louis Mansot

\section{> To cite this version:}

Philippe Bilas, Laurence Romana, Francois Bade, Karl Delbe, Jean-Louis Mansot. Speed and Atmosphere Influences on Nanotribological Properties of NbSe2. Tribology Letters, 2009, vol. 34, pp. 41-48. 10.1007/s11249-008-9400-8 . hal-00780496

\section{HAL Id: hal-00780496 https://hal.science/hal-00780496}

Submitted on 24 Jan 2013

HAL is a multi-disciplinary open access archive for the deposit and dissemination of scientific research documents, whether they are published or not. The documents may come from teaching and research institutions in France or abroad, or from public or private research centers.
L'archive ouverte pluridisciplinaire HAL, est destinée au dépôt et à la diffusion de documents scientifiques de niveau recherche, publiés ou non, émanant des établissements d'enseignement et de recherche français ou étrangers, des laboratoires publics ou privés. 


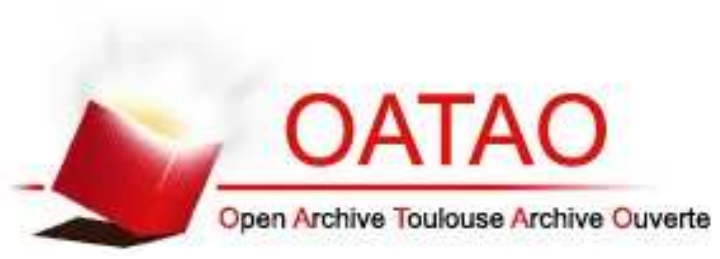

\section{Open Archive Toulouse Archive Ouverte (OATAO)}

OATAO is an open access repository that collects the work of Toulouse researchers and makes it freely available over the web where possible.

This is an author-deposited version published in: http://oatao.univ-toulouse.fr/ Eprints ID: 6345

To link to this article: DOI:10.1007/s11249-008-9400-8

URL: http://dx.doi.org/10.1007/s11249-008-9400-8

\section{To cite this version:}

Bilas, Philippe and Romana, Laurence and Bade, François and Delbe, Karl and Mansot, Jean-Louis Speed and Atmosphere Influences on Nanotribological Properties of NbSe2. (2009) Tribology Letters, vol. 34 (1). pp. 41-48. ISSN 1023-8883

Any correspondence concerning this service should be sent to the repository administrator: staff-oatao@listes.diff.inp-toulouse.fr 


\title{
Speed and Atmosphere Influences on Nanotribological Properties of $\mathrm{NbSe}_{2}$
}

\author{
P. Bilas $\cdot$ L. Romana $\cdot$ F. Bade $\cdot$ K. Delbe $\cdot$ \\ J. L. Mansot
}

\begin{abstract}
Nanotribological properties of $\mathrm{NbSe}_{2}$ are studied using an atomic friction force microscope. The friction force is measured as a function of normal load and scan speeds ranging from $10 \mathrm{~nm} \mathrm{~s}^{-1}$ to $40 \mu \mathrm{m} \mathrm{s}^{-1}$ under two atmospheres (air and argon). At low speed, no effect of atmosphere is noticed and a linear relationship between the friction and normal forces is observed leading to a friction coefficient close to 0.02 for both atmospheres. At high speed, the tip/surface contact obeys the JKR theory and the tribological properties are atmosphere dependent: the shear stress measured in air environment is three times lower than the one measured under argon atmosphere. A special attention is paid to interpret these results through numerical data obtained from a simple athermal model based on Tomlinson approach.
\end{abstract}

Keywords Nanotribology - AFM - Friction mechanisms · $\mathrm{NbSe}_{2}$

\section{Introduction}

The recent development of techniques such as scanning probe microscopies (AFM, FFM) for the measurements of

P. Bilas · L. Romana $(\bowtie) \cdot$ K. Delbe $\cdot$ J. L. Mansot

Groupe de Technologie des Surfaces et des Interfaces, Université des Antilles et de la Guyane, Faculté des Sciences Exactes et Naturelles, Campus de Fouillole, 97159 Pointe à Pitre Cedex, Guadeloupe, France

e-mail: laurence.romana@univ-ag.fr

\section{F. Bade}

Laboratoire de Physique de l'Atmosphère Tropicale, Université des Antilles et de la Guyane, Faculté des Sciences Exactes et Naturelles, Campus de Fouillole, 97159 Pointe à Pitre Cedex, Guadeloupe, France the friction force at the nanometer scale opens promising approaches for a better understanding of the fundamental processes in tribology. Generally, the tip/surface contact is considered as a point contact and represents the simplest experimental model to describe two contacting surfaces. However, the small values of the parameters involved, such as the contact area size and the force intensity, lead to a lack of control of the tribological interface making the interpretation and comparison of data difficult.

Since the first experiments of Mate et al. in 1987 [1] many works have been performed to study the dependence of the nanotribological properties on the load [2-5], scan velocity [6-19], and atmosphere [20-22]. In the last decade, great debates are engaged on the velocity dependence of friction mainly because of contradictory results reported in literature. Velocity independence of the friction force with speed has been reported by Zwörner et al. [8] who measured the $F_{\mathrm{F}}(V)$ curves on several carbon compound substrates. Same observations were reported by Schirmeisen et al. [13] for tests performed on untreated silicon wafers at temperature above $155 \mathrm{~K}$. For lower temperature, they observed a logarithmic increase of friction. The logarithmic law has been reported for nanotribological tests performed at room temperature on ionic substrates such as $\mathrm{NaCl}, \mathrm{KBr}$, mica [10, 11, 17], or metallic $\mathrm{Cu}$ [11]. This behavior is attributed to thermally activated jumps of the contact atoms through the atomic interaction potential barrier. A power-law increase of friction force with scan speed has also been reported [12], and is related to friction controlled by athermal atomic jumps. Recently, Tambe and Bhushan [18] extended the velocity range investigated up to $10 \mathrm{~mm} \mathrm{~s}^{-1}$. They observed several behaviors of the friction force depending on the speed range and attribute these different regimes to different energy dissipation processes with regard to the speed. 
In this work, influences of scan speed and atmosphere on nanotribological properties of $\mathrm{NbSe}_{2}$ are presented. The tribological behaviors are first characterized by the friction forces versus applied load curves for low and high speeds. Since influence of atmosphere on the friction force is found to be speed dependent, systematic studies of the friction force with speed (for a given load) have been investigated. For both atmospheres, the velocity dependence of the friction force can be predicted by a numerical athermal model based on Tomlinson approach [23]. We use this model to interpret the speed and atmosphere dependence in terms of tip displacement on the surface sample.

\section{Experimental Set-Up}

The nanotribological properties of $\mathrm{NbSe}_{2}$ are investigated by means of an atomic friction force microscope (AFFM) from Molecular Imaging Corp. (PICOSPM) coupled with an APEX environmental chamber. The cantilever is mounted on a piezoelectric tube and the tip can scan the fixed surface sample to a maximum area of $6 \mu \mathrm{m} \times 6 \mu \mathrm{m}$. All the tests are performed in the so-called "constant force mode."

The geometric parameters of the rectangular silicon cantilevers purchased from MikroMasch are characterized by electron scanning microscopy prior and after each experiment. The cantilever normal stiffness, $k_{\mathrm{N}}$, is calculated from the thermal noise amplitude method developed by Sader et al. [24]. Normal stiffnesses ranging from 1 to $5 \mathrm{~N} \mathrm{~m}^{-1}$ are measured allowing us to apply normal loads up to $120 \mathrm{nN}$.

Calibrations of the normal and lateral forces are performed using the method developed in $[25,26]$. The friction force is deduced from the conventional friction loop and is defined as $F_{\mathrm{F}}=F_{\text {Lforth }}+F_{\text {Lback }} / 2$ where $F_{\text {Lforth }}$ and $F_{\text {Lback }}$, respectively, are the lateral forces recorded for the forth and back directions of the scan.

The variation of the friction force as a function of the applied load is investigated for scan velocities ranging from $10 \mathrm{~nm} \mathrm{~s}^{-1}$ to $40 \mu \mathrm{m} \mathrm{s}^{-1}$. Such speeds are obtained with scan size areas varying between $4 \mathrm{~nm} \times 4 \mathrm{~nm}$ and $6 \mu \mathrm{m} \times 6 \mu \mathrm{m}$.

The fast scan direction is perpendicular to the cantilever axis and carefully aligned along the [100] axis of the $\mathrm{NbSe}_{2}$ crystal for scan sizes lower than $20 \mathrm{~nm}$ (atomic resolution).

For all experiments, no wear was detected.

Effect of environment on the tribological properties of $\mathrm{NbSe}_{2}$ is investigated through experiments performed under air and argon atmospheres. In the last case, the gas flow is kept lower than $0.2 \mathrm{dm}^{3} \mathrm{~s}^{-1}$ to avoid flow-induced vibrations.
The monocrystalline substrates of $\mathrm{NbSe}_{2}$ are offered by the Nanofabrication Research laboratory from Bell Labs. To perform the AFFM tests on clean substrate, the $\mathrm{NbSe}_{2}$ surface is cleaved with an adhesive tape just before the experiments.

\section{Results and Discussions}

\subsection{Presentation and Validation of the Numerical Model}

To interpret our experimental tribological data, we chose an approach based on Tomlinson model and classically used to describe the motion equations of the tip during stick slip regime. The tip/surface contact is described as a point contact of mass $m$, coupled elastically with the support by a spring of elastic constant $k$, and interacting with the surface via a periodic potential $V_{\mathrm{ts}}(x, y)=V_{0} \cos \left(\left(2 \pi / a_{x}\right) x_{\mathrm{t}}\right)$ $\cos \left(\left(2 \pi / a_{y}\right) y_{\mathrm{t}}\right)$ where $a_{x}$ and $a_{y}$ represent the atomic distances in the surface along the $x$ and $y$ directions. While the support is moving at a constant velocity $V$ the tip moves at a velocity $\dot{x}_{\mathrm{t}}$ and $\dot{y}_{\mathrm{t}}$ along the $x$ and $y$ directions. No thermal fluctuation $[10,11,14,15]$ or multiple points contact [27, 28] are introduced in the model. With such assumptions, the motion equations of the tip are given by:

$m \ddot{x}_{\mathrm{t}}=k_{x}\left(V t-x_{\mathrm{t}}\right)-\frac{\partial V_{\mathrm{ts}}}{\partial x}-\gamma_{x} \dot{x}_{\mathrm{t}}$,

$m_{y} \ddot{y}_{\mathrm{t}}=k_{y}\left(V t-y_{\mathrm{t}}\right)-\frac{\partial V_{\mathrm{ts}}}{\partial y}-\gamma_{y} \dot{y}_{\mathrm{t}}$.

To solve these nonlinear equations, the backward differentiation formula (BDF) method, proposed by Hölsher et al. [29], is used. The suitable parameters $m, \gamma$, $k, V, a$, and $V_{0}$ are deduced from literature and from our experimental data. The effective stiffness $k$ (which represents the resulting spring constant of all the compliant elements of the tip/surface system [30]) is deduced from the variation of the friction force with the piezo displacement (see the friction loop in Fig. 1). Its value corresponds to the slope of the curve measured during the sticking phase. The potential corrugation $V_{0}$ is deduced from the friction force value since $V_{0}=$ $a_{x} F_{\mathrm{F} \max } / 2 \pi$ [2] where $F_{\mathrm{Fmax}}$ is the maximum value of the friction force deduced from the friction force loop (Fig. 1). In this work, the potential corrugation varies from 1 to $3 \mathrm{eV}$. The parameters $a_{x}$ and $a_{y}$ are deduced from the crystallographic parameters of the $\mathrm{NbSe}_{2}$ structure $\left(a_{x}=0.34 \mathrm{~nm}\right.$ and $\left.a_{y}=0.58 \mathrm{~nm}\right) . V$ is the experimental scan speed (ranging from $10 \mathrm{~nm} \mathrm{~s}^{-1}$ to $40 \mu \mathrm{m} \mathrm{s}^{-1}$ ). The effective mass $m\left(m_{x}=m_{y}=m\right)$ and the damping term $\gamma$ $\left(\gamma_{x}=\gamma_{y}\right)$ are difficult to evaluate. Assuming that our tip/ 
Fig. 1 a Lateral force image recorded at the atomic scale on $\mathrm{NbSe}_{2}$ surface as the silicon tip moves from right to left. The inset image corresponds to the numerical lateral force image calculated with $m=10^{-13} \mathrm{~kg}$, $k=10 \mathrm{~N} \mathrm{~m}^{-1}$, $\gamma=10^{-4} \mathrm{~kg} \mathrm{~s}^{-1}$, $V=30 \mathrm{~nm} \mathrm{~s}^{-1}$, and $V_{0}=2 \mathrm{eV} ; \mathbf{b}$ Electronic charge density map of $\mathrm{NbSe}_{2}$ calculated from FLAPW$\mathrm{ab}$ initio method (Wien $2 \mathrm{k}$ code), the dashed line indicates the displacement of the tip during 1D stick-slip motion. The pattern periodicities are the same as those reported in $\mathbf{a} ; \mathbf{c}$ Experimental and $\mathbf{d}$ simulated friction loops deduced on the lateral force images represented in a. Note the good quantitative and qualitative agreements between experimental and simulated data
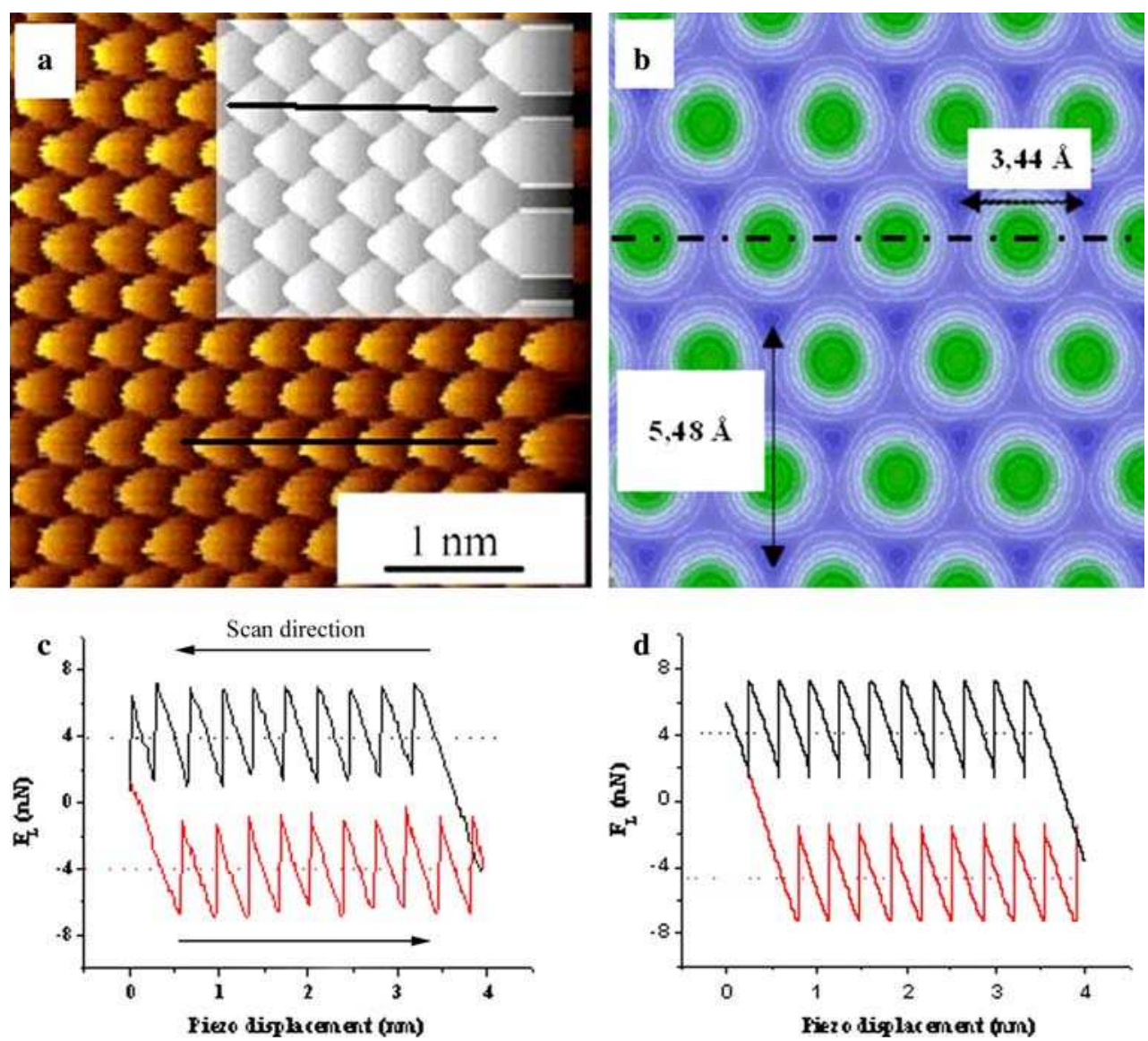

surface system can be approximated by a harmonic oscillator, the torsional resonance frequency is related to the mass and the torsional stiffness $\left(k_{\mathrm{T}}\right)$ by the following expression:

$f_{\mathrm{R}}=\frac{1}{2 \pi} \sqrt{\frac{k_{\mathrm{T}}}{m}}$

Using the values of torsional resonance frequencies reported in literature $(100-500 \mathrm{kHz})[27,31]$, we calculated an effective mass ranging from $10^{-10}$ to $10^{-14} \mathrm{~kg}$. In our calculation no significant modification of the friction force is measured by changing the mass by four order of magnitude $\left(10^{-14}<m<10^{-10} \mathrm{~kg}\right)$. All the calculations presented in this work were performed with an effective mass of $10^{-13} \mathrm{~kg}$. The value of the damping term is estimated by comparing the experimental and theoretical friction force values (see Sect. 3.3).

Experimental and simulated lateral force images are shown in Fig. 1a. The spatial variations of the lateral force intensity are characteristic of a 2D stick-slip motion of the tip on the surface sample. For comparison, an electronic charge density map of $\mathrm{NbSe}_{2}$ calculated from FLAPW ab initio method (Wien 2k code [32]) is shown in Fig. 1b. The maximum (minimum) charge density is located at the middle of the green (blue) circles. A good correlation between the periodicity of the three images is observed. The friction force loops recorded on the experimental and simulated friction force images are reported in Fig. 1c and $\mathrm{d}$, respectively. The lateral force profiles are performed on the row of maximum contrast (indicated by the arrow in Fig. 1a) where the tip is subjected to a 1D stick-slip motion (see dashed-pointed line in Fig. 1b). The good qualitative and quantitative agreements obtained between the experimental and simulated data confirm the relevance of the Tomlinson model to describe the surface/tip interaction during stick-slip in our experimental conditions. It is important to note that the relevant parameters used for the simulations are extracted from our quantitative experimental data.

\subsection{Load Dependence}

The friction force as a function of the normal load $\left(F_{\mathrm{N}}\right)$ is measured to determine the tribological properties of $\mathrm{NbSe}_{2}$. For these tests, two experimental set-ups are used:

- Atomic friction tests for which the scan size is kept at $5 \mathrm{~nm} \times 5 \mathrm{~nm}$ with a constant scan speed of $30 \mathrm{~nm} \mathrm{~s}^{-1}$. 

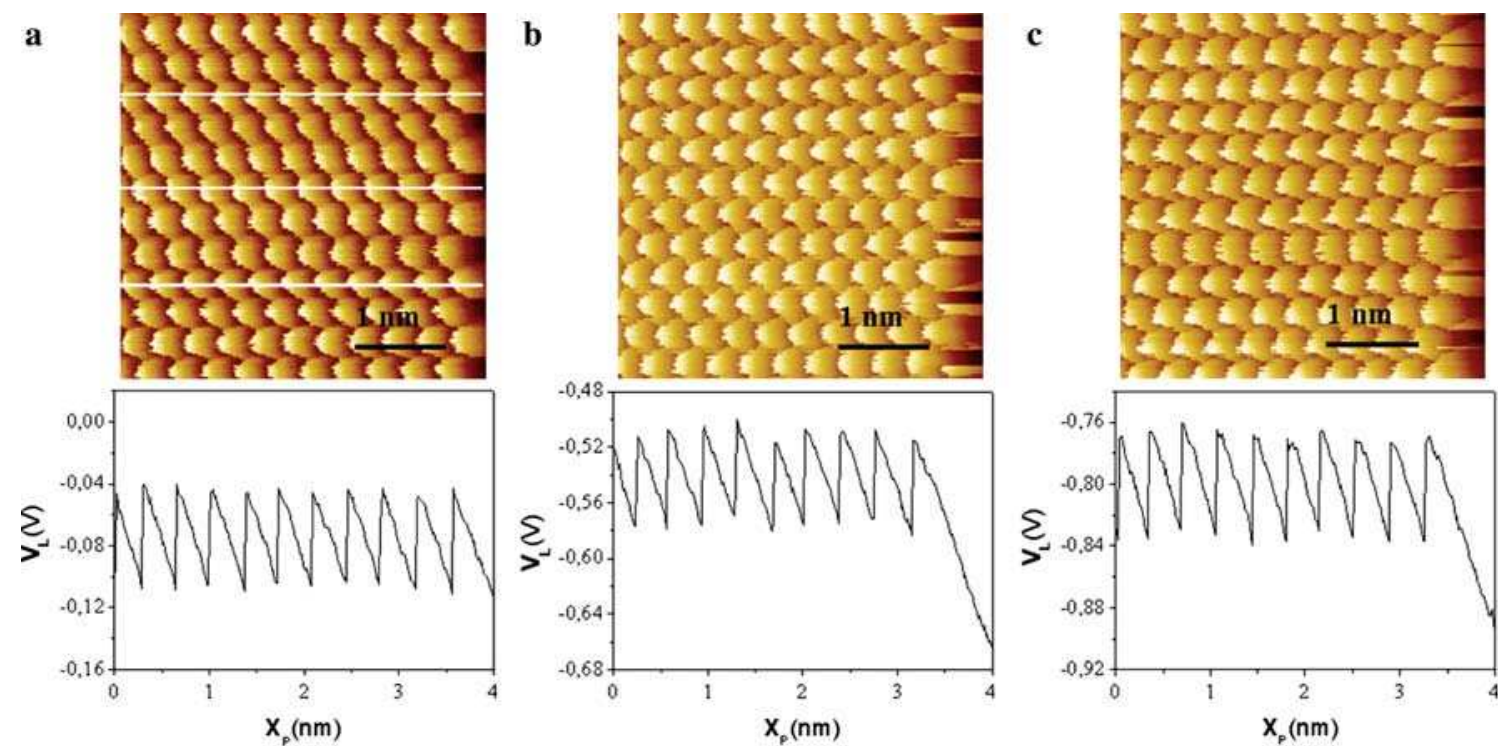

Fig. 2 Experimental lateral force images recorded for a scan speed of $30 \mathrm{~nm} \mathrm{~s}^{-1}$ under air atmosphere for applied loads of a $20 \mathrm{nN}$, b $60 \mathrm{nN}$, and $\mathbf{c} 140 \mathrm{nN}$. The lateral force profile recorded on the row of maximum contrast is reported in the lower part of the picture

- Meso scale friction test performed on $5 \mu \mathrm{m} \times 5 \mu \mathrm{m}$ image size with a scan speed of $15 \mu \mathrm{m} \mathrm{s}^{-1}$.

For indication, the lateral force images recorded at the atomic scale for normal loads of 28,60 , and $140 \mathrm{nN}$ are shown in Fig. 2. The lateral force profile measured on the row of maximum contrast (indicated by the white line in Fig. 2a) and reported on the lower part of the picture evidences the stick-slip motion of the tip at such speed for the whole applied load investigated.

The friction forces as a function of the total normal load $F_{\mathrm{N}}$ (applied load plus pull-off force) measured at the atomic and meso scales are reported in Figs. 3 and 4 respectively, for both atmospheres. Note that due to the piezo curvature during the scan, the applied load varies continuously (in a controlled manner) during a $5 \mu \mathrm{m} \times 5 \mu \mathrm{m}$ scan size allowing us to record on one image $256 F_{\mathrm{F}}\left(F_{\mathrm{N}}\right)$ data points $(256 \times 256$ pixels per image). More details are available in $[25,26]$. For the atomic friction experiments, due to the small size of the scan $(5 \mathrm{~nm} \times 5 \mathrm{~nm})$, the applied load is constant on the whole image. This explains the lower number of points reported on the $F_{\mathrm{F}}\left(F_{\mathrm{N}}\right)$ curves measured at the atomic scale.

At the atomic scale (Fig. 3), the friction force linearly increases with total load regardless of atmosphere. No significant effect of atmosphere is observed. The linear relationship between the friction and normal forces, allows us to characterize the sliding interface by a dynamic friction coefficient $\mu$ defined as $\Delta F_{\mathrm{L}} / \Delta F_{\mathrm{N}}$. The friction coefficient measured from 20 tests performed in air and 5 performed under argon are similar for both atmospheres: the average friction coefficient is equal to $0.016 \pm 0.003$ under air and $0.010 \pm 0.006$ under argon.

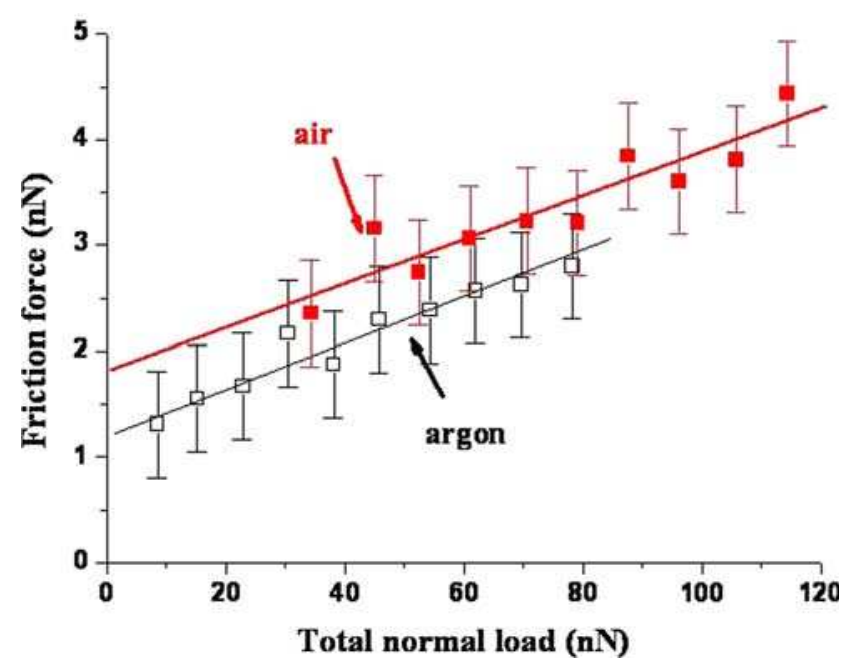

Fig. 3 Friction forces measured as a function of total normal load for atomic scale experiments performed under air (filled square) and argon (open square) atmospheres. The scan size is kept at $5 \mathrm{~nm} \times 5 \mathrm{~nm}$ and the scan speed is $30 \mathrm{~nm} \mathrm{~s}^{-1}$. The mean square linear fits are represented by the lines for air and argon atmospheres and lead to similar friction coefficient

The $F_{\mathrm{F}}\left(F_{\mathrm{N}}\right)$ curves measured at meso scale (Fig. 4) indicate a nonlinear relationship between the friction force and total normal load. For such behavior, the friction is generally expressed as $F_{\mathrm{F}}=\tau A$, where $\tau$ is the shear stress of the sliding interface and $A$ is the real contact area. Contact mechanic theories are required to deduce $\tau$ and $A$ from the $F_{\mathrm{F}}\left(F_{\mathrm{N}}\right)$ curve and the knowledge of the tip radius and reduced elastic modulus $E^{*}$ of the encountered surfaces are needed. According to literature, the reduced elastic modulus of $\mathrm{NbSe}_{2} / \mathrm{Si}$ interface is equal to $40 \mathrm{GPa}$ [33]. The geometry of the tip is measured by scanning 


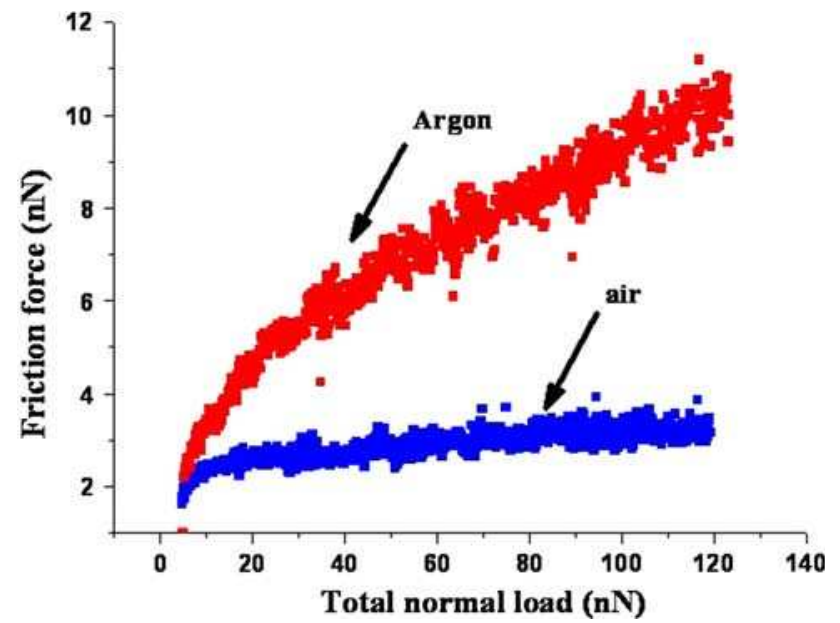

Fig. 4 Friction forces measured as a function of total normal load for meso scale experiments performed under air and argon atmospheres. The scan size is kept at $5 \mu \mathrm{m} \times 5 \mu \mathrm{m}$ and the scan speed is $15 \mu \mathrm{m} \mathrm{s}^{-1}$. The $F_{\mathrm{F}}\left(F_{\mathrm{N}}\right)$ curves are well fitted by the JKR theory for both atmospheres as represented by the fitted curves indicated by the solid lines. The shear stress measured under argon is three times higher than the one measured under air

electron microscopy before and after the AFFM tests. No significant evolution of the tip is observed for the data reported in Fig. 4 and the tip radius measured is close to $60 \mathrm{~nm}$.

For both atmospheres investigated, the $\mathrm{NbSe}_{2} / \mathrm{Si}$ contacts obey the JKR theory. The fitted data are represented by the solid line curves in Fig. 4. From the 20 tribological tests performed, the average shear stress value $\tau$ deduced from the fitted curve is of the order of $15 \mathrm{MPa}$ in air and $45 \mathrm{MPa}$ in argon. The differences observed between the experimental and fitted curves for small applied load $\left(F_{\mathrm{N}}<10 \mathrm{nN}\right)$ have already been reported and attributed either to a contaminant layer at the surface [34] or to the mechanical properties of the extreme surface [35].

\subsection{Speed Influence}

According to the data reported in Figs. 3 and 4, influence of atmosphere is only significant at high-speed regime. To investigate such behavior, systematic studies of the friction force as a function of speed for both atmospheres are performed. Figure 5 shows the evolution of the friction force as a function of the scan speed (on a logarithmic scale) for both atmospheres at a constant normal load. Both curves are recorded with the same tip. The errors bars reported on Fig 5 correspond to the forces variations measured on different images recorded for the same load and scan speed.

Regardless of the atmosphere, two different speed regimes are observed:

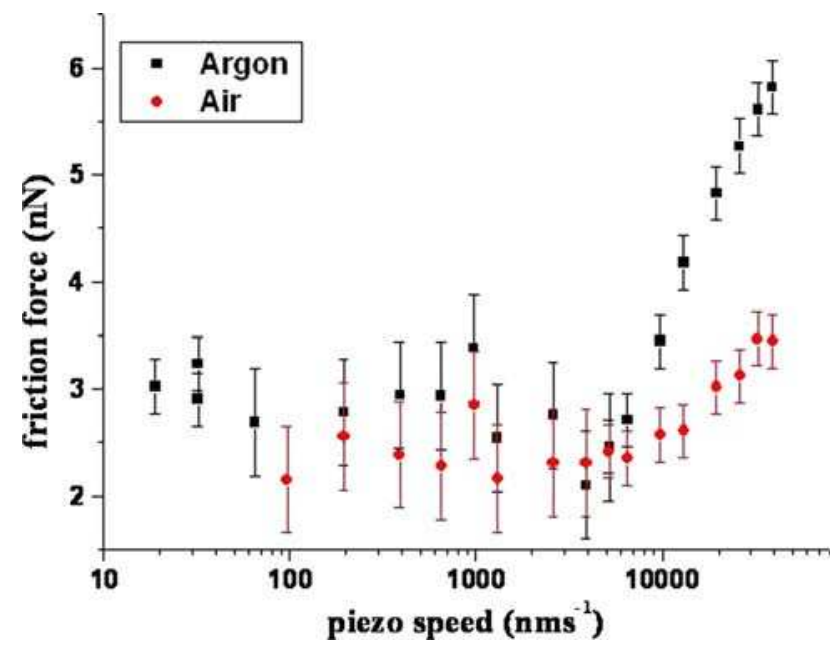

Fig. 5 Friction forces measured as a function of piezo speed for air (circles) and argon (squares) atmospheres. The tests are performed for total applied load of 50 and $70 \mathrm{nN}$ for air and argon atmospheres, respectively

- The low-speed regime where the friction force does not change significantly with speed regardless of the environment.

- The high-speed regime where the friction force increases with speed. This increase is atmosphere dependent.

At low speed (lower than few $\mu \mathrm{m} \mathrm{s}^{-1}$ ), the friction forces measured under air and argon atmospheres are similar which indicates that the tip experiences the same interaction potential. The slight higher values of the friction forces measured under argon are attributed to the higher total normal load applied to record this curve $\left(F_{\mathrm{N}}\right.$ is equal to $50 \mathrm{nN}$ under air and $70 \mathrm{nN}$ under argon). On the contrary, at high speed, the friction force measured and its variation with speed are significantly higher under argon than under air which seems to indicate different sliding surfaces.

To investigate the role played by the atmosphere, numerical simulations are performed. It is obvious that thermal-activated processes do not play an important role in our experiments, since most of the theoretical thermal models predict either a logarithmic or $|\operatorname{Ln}(V)|^{2 / 3}$ friction dependency with speed [14-16, 19]: the curves presented in Fig. 5 do not obey such laws. The best agreement between simulated and experimental $F_{\mathrm{F}}(V)$ curves is obtained for numerical data extract from the athermal model described in Sect. 3.2. The two simulated parameters of interest in this work are the friction force and the tip displacement on the surface sample (characterized by the tip velocity). The curves simulated with the experimental parameters $V_{0}(2 \mathrm{eV})$ and $k\left(8 \mathrm{~N} \mathrm{~m}^{-1}\right)$ are represented in Figs. 6 and 7. 


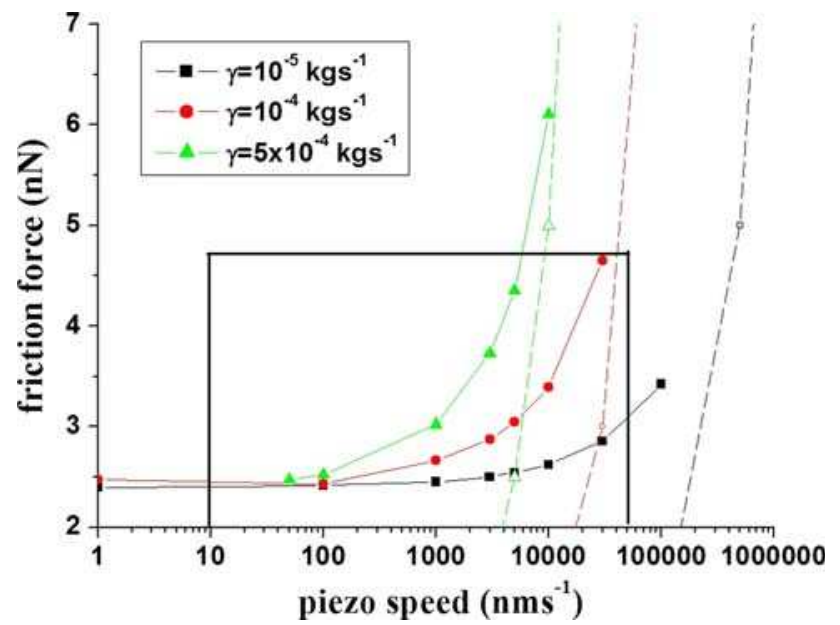

Fig. 6 Simulated friction force as a function of the scan speed for different damping coefficients: $\gamma=10^{-5} \mathrm{~kg} \mathrm{~s}^{-1}$ (squares), $\gamma=$ $10^{-4} \mathrm{~kg} \mathrm{~s}^{-1}$ (circles), and $\gamma=5 \times 10^{-5} \mathrm{~kg} \mathrm{~s}^{-1}$ (triangles). The parameters used for the simulation are $m=10^{-13} \mathrm{~kg}, k=10 \mathrm{~N} \mathrm{~m}^{-1}$, and $V_{0}=2 \mathrm{eV}$. The dashed lines represent the corresponding viscous friction force $(F=\gamma V)$. The square zone indicates the speed range experimentally investigated

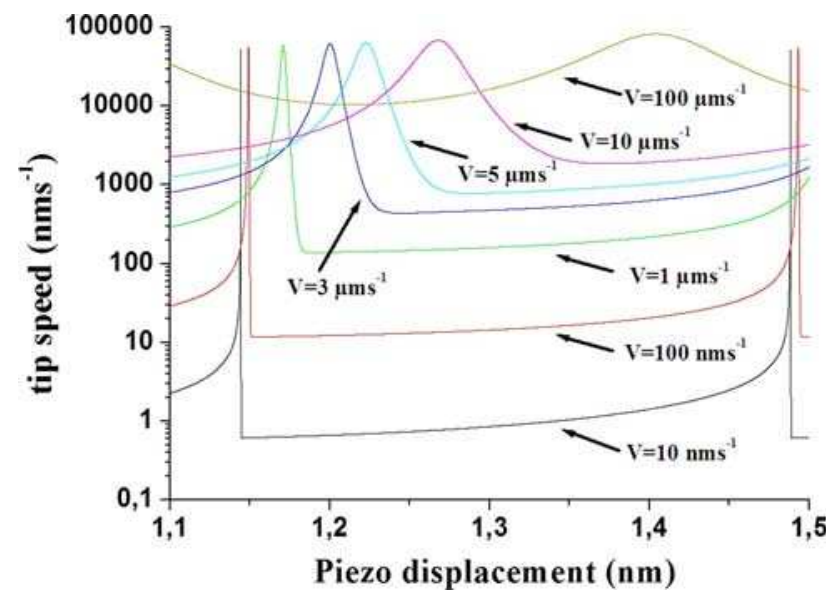

Fig. 7 Simulated tip velocity as a function piezo position for different scan speeds. The parameters used for the simulation are $m=10^{-13} \mathrm{~kg}, \gamma=10^{-4} \mathrm{~kg} \mathrm{~s}^{-1}, k=10 \mathrm{~N} \mathrm{~m}^{-1}$, and $V_{0}=2 \mathrm{eV}$. The sudden jump of the tip speed is attributed to the slip phase. Note that tip is moving during the so-called "stick phase" since its speed is always higher than zero

Figure 6 represents the simulated friction forces versus piezo speed for damping term values ranging from $10^{-5}$ to $5 \times 10^{-4} \mathrm{~kg} \mathrm{~s}^{-1}$. The dashed lines correspond to the viscous force $\left(F_{\mathrm{F}}=\gamma V\right)$ for each damping term and the dashed square zone indicates the speed range experimentally investigated. At low speed, the friction force is the same for different damping coefficient whereas at high speed the friction force and the slope of the $F_{\mathrm{F}}(V)$ curves increase with the damping term value. At high piezo velocity, the friction force is close to the viscous force due to a continuous motion of the tip. The simulated $F_{\mathrm{F}}(V)$ curves show the same trend as the experimental ones (Fig. 5), confirming the relevance of the athermal Tomlinson model to describe our results. A simple comparison between the experimental and simulated data indicates that the damping term is higher under $\operatorname{argon}\left(\gamma \approx 10^{-4} \mathrm{~kg} \mathrm{~s}^{-1}\right)$ than under air $\left(\gamma \approx 10^{-5} \mathrm{~kg} \mathrm{~s}^{-1}\right)$ atmospheres. These values are compatible with the one recently proposed by Yabing et al. [36] for experiments performed on doped silicon.

The tip speed (expressed in a logarithmic scale) as a function of the piezo displacement is shown in Fig. 7 for several piezo speeds and for a damping term of $10^{-4} \mathrm{~kg} \mathrm{~s}^{-1}$. The slip phase of the tip motion is characterized by the sudden jumps observed whereas the stick phase corresponds to the smooth variations of the tip velocity. Note that, during the stick phase, the velocity is not equal to zero indicating that the tip is not at rest during the so-called stick phase. In this phase, the tip slides more rapidly as the piezo velocity increases (higher tip speed values).

Due to the hydrophilic property of $\mathrm{NbSe}_{2}$ [26], it is reasonable to assume that the water layer adsorbed on the surface is thicker under air atmosphere (55\% relative humidity) than under argon. One would expect in such case to measure lower friction force under air due to potential screening effects. This is observed experimentally for scan speeds higher than few $\mu \mathrm{m} \mathrm{s}^{-1}$ but not for lower speeds where friction appears to be atmosphere independent. We believe that the different effect of atmosphere on friction for the low- and high-speed regimes is related to the tip displacement:

- For the lower scan speed, due to the low tip velocity during the stick phase (Fig. 7), the duration of interaction between the two sliding surfaces is high enough to allow molecules desorption (probably through mechanical actions). In such case, the sliding surfaces experience the same interaction potential leading to similar friction forces regardless of the atmospheres.

- As the piezo speed increases (higher tip speed in the stick phase, see Fig. 7), the tip does not have time to push away the adsorbed molecules and influence of atmosphere becomes important.

For the critical speed (or critical range speed) at which the adsorbed molecules remain on the surface, one should expect to observe a decrease of the friction force (due to screening effect) and then an increase of the friction force as the speed increases (due to viscous effect). Such behavior has been observed for $40 \%$ of the experiments. A typical friction $F_{\mathrm{F}}(V)$ curve showing this trend and recorded under air, for total applied load of $50 \mathrm{nN}$, is reported in Fig. 8. The decrease of the friction force for scan velocity close to $1 \mu \mathrm{m} \mathrm{s}^{-1}$ evidences the screening effect due to the 


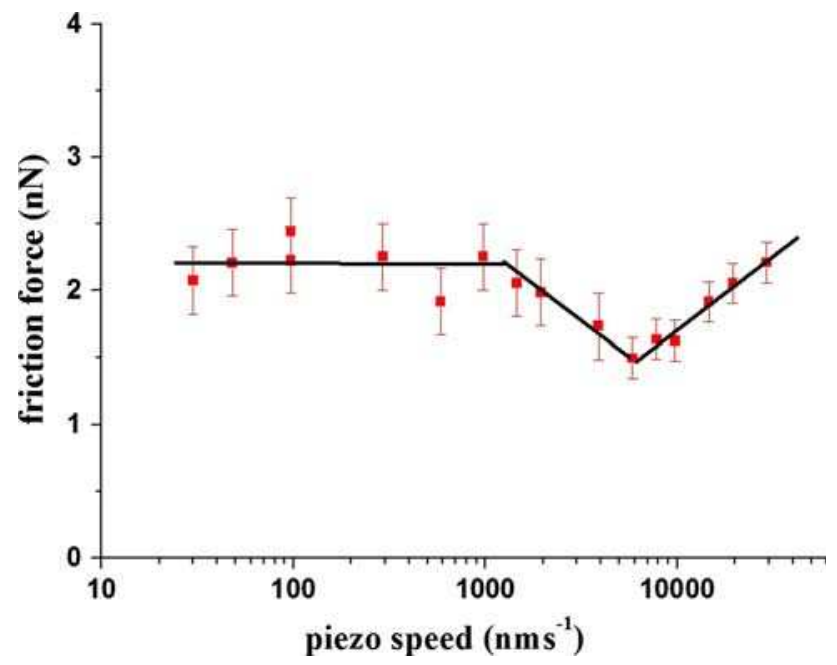

Fig. 8 Friction forces measured under air as a function of piezo speed for applied load. This curve is obtained under the same condition as the one reported in Fig. 5 but shows a different behavior. The decrease of the friction force value around $1 \mu \mathrm{m} \mathrm{s}^{-1}$ is attributed to the interaction potential screening due to the adsorbed molecules. Such a trend is observed for $40 \%$ of the experiments

stable adsorbed molecules. Viscous effect appears dominant at speed higher than $5 \mu \mathrm{m} \mathrm{s}^{-1}$. For the $F_{\mathrm{F}}(V)$ curves reported in Fig. 5, viscous effect is always the prevailing effect. The reason why one of these two antagonist effects becomes relevant during high-speed experiment is not understood yet. Ultrahigh vacuum tests are in progress to study separately the two effects.

A change in the friction force could also be induced by a tip structure modification. Since in our experiments the decrease of $F_{\mathrm{F}}$ (when observed) always occurs for scan speed close to $1 \mu \mathrm{m} \mathrm{s}^{-1}$, such hypothesis can be ruled out.

Note that the difference observed for the damping term values deduced from air and argon experiments is probably due to the presence of the thicker adsorbed layer at the $\mathrm{NbSe}_{2}$ surface under air atmosphere. The presence of this adsorbed layer should induce a change in the dissipation mechanisms at the substrate surface. Reimann and Evstigneev [19] have pointed out the importance of the relative dissipative terms induced by the substrate or the cantilever on friction behavior at atomic scale.

\section{Conclusion}

Effects of scan speed $\left(10 \mathrm{~nm} \mathrm{~s}^{-1}<V<40 \mu \mathrm{m} \mathrm{s}^{-1}\right)$ and atmosphere (air or argon) on the nanotribological properties of $\mathrm{NbSe}_{2}$ have been investigated by means of atomic force friction microscopy. The dependence of the friction force with scan speed is satisfactorily described by an athermal mechanical approach based on the Tomlinson model. Influence of atmosphere on the nanotribological properties is only noticeable at high speed (higher than few $\mu \mathrm{m} \mathrm{s}^{-1}$ ). Comparison between the numerical and simulated data leads to the following interpretations:

- At low speed, the tip trapped into the minimum interaction potential has enough time to interact with the adsorbed molecules and push them away from the contact leading to the same sliding interfaces and same tribological properties

- At high speed, the interaction time of the contacting atoms is too short to induce molecules desorption (the sliding velocity of the tip in the "stick phase" is too high): the adsorbed molecule layers is thicker under air than under argon, leading to a lower interaction potential and probably a lower damping term.

This study demonstrates that the atmosphere environment is not the only parameter which determines the true environment inside the contact area. Recently, $\mathrm{Xu}$ et al. [37] reached the same conclusion, but in their study the interfacial conditions were controlled by the shear strength inside the contact. In this study, environment inside the contact is found to be tip speed related.

Acknowledgments The authors wish to thank the $\mathrm{C}^{3} \mathrm{I}$ for its technical support in collecting computational data and Molecular Imaging for its technical help. The authors acknowledge the Conseil Regional de la Guadeloupe and the Fond social Europeen for its financial supports.

\section{References}

1. Mate, C.M., McClelland, G.M., Erlandsson, R., Chiang, S.: Atomic-scale friction of a tungsten tip on a graphite surface. Phys. Rev. Lett. 59, 1942-1945 (1987). doi:10.1103/PhysRev Lett.59.1942

2. Socoliuc, A., Bennewitz, R., Gnecco, E., Meyer, E.: Transition from stick-slip to continuous sliding in atomic friction: entering a new regime of ultralow friction. Phys. Rev. Lett. 92(13), 134301134304 (2004). doi:10.1103/PhysRevLett.92.134301

3. Fujisawa, S., Yokoyama, K., Sugawara, Y., Morita, S.: Analysis of experimental load dependence of two-dimensional atomicscale friction. Phys. Rev. B 58(8), 4909-4916 (1998)

4. Sasaki, N., Tsukada, M., Fujisawa, S., Sugawara, Y., Morita, S., Kobayashi, K.: Load dependence of the frictional-force microscopy image pattern of the graphite surface. Phys. Rev. B 57(7), 3785-3786 (1998). doi:10.1103/PhysRevB.57.3785

5. Miura, K., Sasaki, N., Kamiya, S.: Friction mechanisms of graphite from a single-atomic tip to a large-area flake tip. Phys. Rev. B 69, 075420-075429 (2004). doi:10.1103/PhysRevB.69. 075420

6. Bennewitz, R., Gyalog, T., Guggisberg, M., Bammerlin, M., Meyer, E., Güntherodt, H.J.: Atomic-scale stick-slip processes on Cu(111). Phys. Rev. B 60(16), 11301-11304 (1999). doi:10.1103/ PhysRevB.60.R11301

7. Hölsher, H., Schirmeisen, A., Schwarz, U.D.: Principles of atomic friction: from sticking atoms to superlubric sliding. Philos. Trans. R. Soc. A 366, 1383-1404 (2008). doi:10.1098/rsta. 2007.2164 
8. Zwörner, O., Hölscher, H., Schwarz, U.D., Wiesendanger, R.: The velocity dependence of frictional forces in point-contact friction. Appl. Phys. A 66, 263-267 (1998)

9. Miura, K., Tsuda, D., Kaneta, Y., Harada, R., Ishikawa, M., Sasaki, N.: Dynamics of graphite flake on a liquid. Appl. Phys. Lett. 89, 2231041-2231043 (2006). doi:10.1063/1.2397035

10. Riedo, E., Gnecco, E., Bennewitz, R., Meyer, E., Brune, H.: Interaction potential and hopping dynamics governing sliding friction. Phys. Rev. Lett. 91(8), 845021-845024 (2003). doi: 10.1103/PhysRevLett.91.084502

11. Bennewitz, R., Gnecco, E., Gyalog, T., Meyer, E.: Atomic friction studies on well-defined surfaces. Tribol. Lett. 10(1), 51-56 (2001). doi:10.1023/A:1009078329570

12. Prioli, R., Rivas, A.M.F., Freire, F.L., Caride, A.O.: Influence of velocity in nanoscale friction processes. Appl. Phys. A 76, 565569 (2003)

13. Schirmeisen, A., Jansen, L., Hölsher, H., Fuchs, H.: Temperature dependence of point contact friction on silicon. Appl. Phys. Lett. 88, 1231081-1231083 (2006). doi:10.1063/1.2187575

14. Nakamura, J., Wakunami, S., Natori, A.: Double-slip mechanism in atomic-scale friction: Tomlinson model at finite temperatures. Phys. Rev. B 72, 2354151-2354156 (2005)

15. Fusco, C., Fasolini, A.: Velocity dependence of atomic scale friction: a comparative study of the one and two dimensional Tomlinson model. Phys. Rev. B 71, 0454131-0454139 (2005). doi:10.1103/PhysRevB.71.045413

16. Evstigneev, M., Riemann, P.: Velocity dependence of atomic friction: rate theory and beyond. In: Gnecco, E., Meyer, E. (eds.) Fundamentals of Friction and Wear on the Nanoscale, pp. 117142. Springer-Verlag, Berlin (2007)

17. Gnecco, E., Bennewitz, R., Gyalog, T., Loppacher, C., Bammerlin, M., Meyer, E., Güntherodt, H.J.: Velocity dependence of atomic friction. Phys. Rev. Lett. 84(6), 1172-1174 (2000). doi: 10.1103/PhysRevLett.84.1172

18. Tambe, N.S., Bhushan, B.: Friction model for the velocity dependence of nanoscale friction. Nanotechnology 16, 23092324 (2005). doi:10.1088/0957-4484/16/10/054

19. Reimann, P., Evstigneev, M.: Nonmonotonic velocity dependence of atomic friction. Phys. Rev. Lett. 93, 2308021-2308024 (2004). doi:10.1103/PhysRevLett.93.230802

20. Hu, J., Xiao, X.D., Ogletree, D.F., Salmeron, M.: Atomic scale friction and wear of mica. Surf. Sci. 327, 358-370 (1995)

21. Schwarz, U.D., Zwörner, O., Köster, P., Wiesendanger, R.: Quantitative analysis of the frictional properties of solid materials at low loads. I. Carbon compounds. Phys. Rev. B 56(11), 69876996 (1997). doi:10.1103/PhysRevB.56.6987

22. Putman, C.A.J., Kaneko, R.: Experimental observation of singleasperity at the atomic scale. Thin Solid Films 273, 317-321 (1996)

23. Tomlinson, G.A.: A molecular theory of friction. Philos. Mag. Ser. 7(46), 905-940 (1929)
24. Sader, J.E., Chon, J.W., Mulvaney, P.: Calibration of rectangular atomic force microscope cantilevers. Rev. Sci. Instrum. 70(10), 3967-3969 (1999). doi:10.1063/1.1150021

25. Bilas, P., Romana, L., Kraus, B., Bercion, Y., Mansot, J.L.: Quantitative characterization of friction coefficient using lateral force microscope in the wearless regime. Rev. Sci. Instrum. 75(2), 1-7 (2004). doi:10.1063/1.1637436

26. Bilas, P.: Approche quantitative des phénomènes de frottement à l'échelle atomique et méso échelle par microscopie à force de frottement. PhD Thesis, Universite des Antilles et de la Guyane (2006)

27. Maier, S., Sang, Y., Filleter, T., Grant, M., Bennewitz, R., Gnecco, E., Meyer, E.: Fluctuations and jump dynamics in atomic friction experiments. Phys. Rev. B 72, 2454181-2454189 (2005). doi:10.1103/PhysRevB.72.245418

28. Krylov, S.Y., Dijksman, J.A., Van Loo, W.A., Frenken, J.W.M.: Stick-slip motion in spite of a slippery contact: do we get what we see in atomic friction? Phys. Rev. Lett. 97, 1661031-1661034 (2006). doi:10.1103/PhysRevLett.97.166103

29. Hölsher, H., Schwarz, U.D., Wiensendanger, R.: Modelling of the scan process in lateral force microscopy. Surf. Sci. 375, 395-402 (1997). doi:10.1016/S0039-6028(96)01285-X

30. Colchero, C., Meyer, E., Marti, O.: Friction on an atomic scale. In: Bushnam, B. (ed.) Handbook of Micro/Nano Tribology. CRC Press, Boca Raton (1999)

31. Socoliuc, A., Gnecco, E., Maier, S., Pfeiffer, O., Baratoff, A., Bennewitz, R., Meyer, E.: Atomic-scale control of friction by actuation of nanometer sized contacts. Science 313, 207-210 (2006). doi:10.1126/science.1125874

32. Blaha, P., Schwarz, K., Madsen, G.K.H., Kvasnicka, D., Luitz, J.: WIEN2k: an augmented plane wave local orbitals program for calculating crystal properties. Techn. Universität Wien, Austria (2001)

33. Lantz, M.A., O'Shea, S.J., Hoole, A.C.F., Welland, M.E.: Lateral stiffness of the tip and tip-sample contact in friction force microscopy. Appl. Phys. Lett. 70(8), 970-972 (1996). doi:10.1063/ 1.118476

34. Carpick, R.W., Ogletree, D.F., Salmeron, M.: A general equation for fitting contact area and friction vs load measurements. J. Colloid Interface Sci. 211, 395-400 (1999). doi:10.1006/jcis. 1998.6027

35. Pietrement, O.: Imagerie et caractérisation nanomécanique des surfaces par microscopie à force atomique, $\mathrm{PhD}$ thesis, Université de Reims Champagne Ardennes (2000)

36. Yabing, Q., Park, J.Y., Hendriksen, B.L.M., Ogletree, D.F., Salmeron, M.: Electronic contribution to friction on GaAs. Phys. Rev. B77, 184105-1-184105-7 (2008)

37. Xu, D., Chandar, R., Lietchi, K.M.: On scale dependence in friction: transition from intimate to monolayer-lubricated contact. J. Colloid Interface Sci. 318, 507-519 (2008). doi:10.1016/ j.jcis.2007.09.086 